P. PRABHAKARAN*\#, R. RANGANATHAN**, V. MUTHU KUMAR***,

R. RAJASEKAR*, L. DEVAKUMAR*, S.K. PAL****

\title{
REVIEW ON PARAMETERS INFLUENCING THE RICE BREAKAGE AND RUBBER ROLL WEAR IN SHELLER
}

\begin{abstract}
The present review deals with parameters influencing the rice breakage during rice milling operations and the effect of rubber roll Sheller in rice husk removal process. The main objective of rice milling system is to remove the husk and bran layer to produce the white rice. In this process, rubber roll sheller is used to remove husk from the grains by friction process. If the rubber material is too soft, there may not be sufficient shear force to husk the paddy. Wear will be minimum for rubber material with high hardness but indeed it pronounce the breakage of rice. Hence, for efficient husking the rubber roll material should possess the balance of physico-mechanical properties. Rice breakage depends on several other parameters like the type of harvest, drying temperature, drying methods, physical characteristics of paddy, husking characteristics, paddy moisture content, rubber roller speed, rubber roll pressure, paddy feed rate and fissures. Rubber roll wear depends on the type of rubber material attached to the roller, feed rate, roller speed, pressure etc.
\end{abstract}

Keywords: rice, rice breakage, rubber roll sheller

\section{Introduction}

Rice is one of the most important staple foods for human beings. In Asia-Pacific region 90 percent of the world's rice is produced and consumed [1]. Rice contributes $50-80 \%$ of the calories of the people diet. India is one of the world's largest producers of both white rice and brown rice. Rice production in India increased from 157.8 million tons in 2012 to 159.32 million tons in 2013 [FAOSTAT, 2013]. Rice milling is the final step in post harvesting processing. A rice kernel is covered by two layers. The outer layer is called husk and the inner layer is called bran. The husk is not tightly attached to paddy rice and it is easily removed. But removal of bran layer is difficult because the layer is tightly attached to rice kernels. The rice is removed from the paddy by means of several processes like pre-cleaning, drying, shelling, milling, enriching, whitening, and polishing. The husk layer of the rice is removed by the process called shelling. The process of removing the bran layer is called whitening [2]. The whole white rice is produced in milling industry at different levels [3].

\section{Rice milling}

The objective of rice milling system is to remove the husk and the bran layer to produce white rice. Rice milling can be undertaken at three levels (one step milling process, two step milling process and multistage milling process) [2]. When the husk and bran layer is removed in one process and the white rice is directly produced from the paddy, it is called one step milling process. The husk and the bran layer is removed separately and the brown rice is produced as an intermediate product, it is called two step milling process. The rice is passed through a number of different operations and machines from paddy to white rice is called multistage milling process.

The multistage milling process contain different levels like pre-cleaning, removing the husk and polishing. During precleaning the paddy is cleaned before milling and the next step involves separating husk from the paddy. Removal of husk layer from the paddy by friction process is called de-husking (or) dehulling. The different types of husking machines are steel huller, under runner disc sheller and rubber roll sheller. The steel huller and under runner disc sheller have very low milling efficiency and hulling efficiency [2]. Economic values of the grains based upon yield of the grain and percentage of head rice yield. This study relates the relation between the effect of flowering and yield of the grains. Duration of flowering, rate of flowering, heading, duration from heading to maturity on head rice, and total milling percentage of rice are considered as a parameter to obtain a good quality on grains during milling. It is evident that more flowering days were favorable in increasing head rice and total milled

\footnotetext{
* KONGU ENGINEERING COLLEGE, DEPARTMENT OF MECHANICAL ENGINEERING, PERUNDURAI, ERODE, INDIA

** COIMBATORE INSTITUTE OF TECHNOLOGY, COIMBATORE, INDIA

*** KONGUNADU COLLEGE OF ENGINEERING AND TECHNOLOGY, THOLURPATTI, THOTTIYAM, INDIA

**** INDIAN INSTITUTE OF TECHNOLOGY, KHARAGPUR, INDIA

\# Corresponding author: prabakr.p@gmail.com
} 
grains with high quality [4]. Bold grained rice, IR-36 rice varieties are milled using friction laboratory mill. Prolonged continues milling showing effect on polishing of grains. Grain breakage occurs during high degree of milling and it reduces the quality of rice [5]. Abrasion coefficient of rice is determined at various degrees of milling levels. Average values of abrasion coefficient of rice is used to predict the degree of milling [6]. Head rice yield and whiteness could be successfully modeled during milling operation in relation to the physical and chemical properties of rice [7]. Improved vertical mill helps to mill the grains with the moisture content of $15-16.5 \%$. Rice moisture content, shaft speed of the mill on embryo adherence ratio, whiteness, broken rice ratio, and cracked ratio are the parameters considered to obtain good milling operation [8]. Pneumatic polishing of rice is the improved technology to obtain less percentage of broken rice during milling operation as compared with conventional milling [9]. FAR052, nerical and FAR055 are taken for milling operation. This milling operation is carried on locally developed rice milling machine. Evaluation of this milling process helps to study the performance evaluation of any rice milling machine [10]. Milling co-efficient indicates the required surface area for different types of rice. The surface area requirement is high for long slender type of rice [11]. High degree of milling reduce the content in rough rice such as lipids, proteins, fiber and ash content. Meanwhile the carbohydrate content get increased during high degree of milling. Minimal polished rice are harder and requires more time for cooking. Degree of milling (DOM) affects the appearance of kernel, cumulative energy and head rice yield [12].

\section{Rubber roll sheller}

The rubber roll sheller is the most efficient hulling machine and have high hulling efficiency. The schematic diagram of rice milling process is shown in the Fig. 1.The rubber which is used in the shelling process should be prepared in consideration with the following requirements: Young's modulus 0.54 GPa, Poisson's ratio 0.45 and resistance to heat as the shelling machine can work for more than 24 hours without stopping. The two rubber rollers are having same diameter and operated at different speeds to remove the husk layer from the paddy. One roller

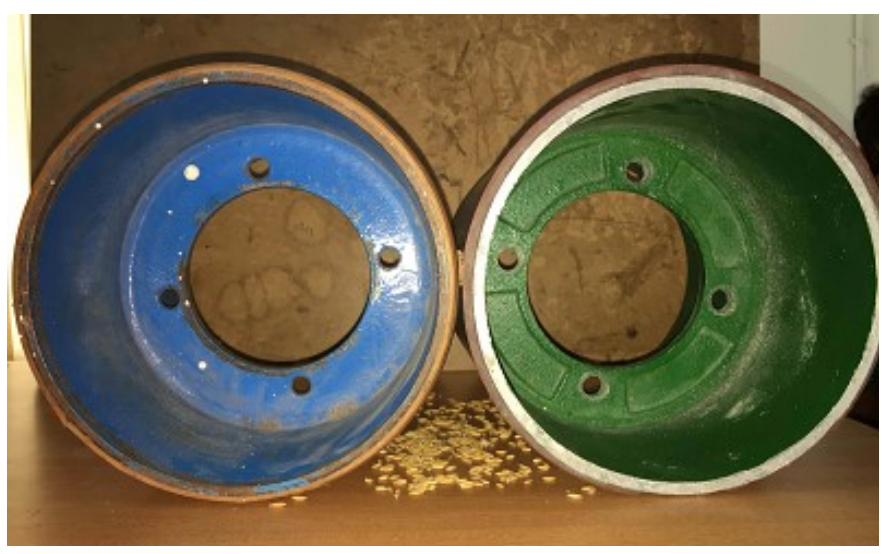

Fig. 1. Schematic of rice milling process is in fixed position and another roller is adjustable to meet the desired clearance. The adjustable roller rotates slower than the fixed roller. The rubber roll sheller has less percentage of rice breakage compared with friction whitener sheller [2]. The rubber roll husker have high husking efficiency compared to impeller husker. It have optimal husked ratio, system cracked ratio and system broken ratio $[13,14]$. Percentage of broken rice was reduced by achieving two stage milling process (husking by rubber huller, polishing by mill) [5].

\section{Drying temperature}

Drying is one of the stage in rice milling. Paddy rice moisture content depends on harvesting method. Initially paddy rice has high moisture content and it is reduced in drying [15]. The rice kernel must be harder when dried at high temperature and low moisture gradient conditions. So the head rice yield is maximum at high drying temperature and low moisture content [16]. Drying duration and moisture content gradient has high impact on head rice yield. If drying duration is high the head rice yield (HRY) is low [17]. The drying rate constant is directly related with the head rice yield reduction and the head rice yield reduction is increased with drying duration at given drying rate constant [18]. Effect of drying and tempering treatments affects head rice yield and rice kernel fissuring [19]. High drying rate with high temperature air forms the rice kernel breakage [20]. Fissured kernals are reduced by means of induced different temperature cycles and by tempering treatments on grains. Tempering at high temperature reduce the percentage of fissured kernals and also enhanced the head rice yield [21]. Fissuring condition of the grains correlate with the yield of head rice. This correlation assist to find the optimum drying and tempering conditions to dry the grains perfectly. This optimum drying and tempering temperatures improves the milling quality and kernel physical integrity [22].

\section{Drying condition}

Typically, fresh paddy contains $28 \%$ moisture content. Drying is carried out using modified air at 30 and $40^{\circ} \mathrm{C}$, hot air at 40,50 and $70^{\circ} \mathrm{C}$. Moisture content of paddy will be reduced to $13-15 \%$. The sun drying consumes higher drying time compared to all other drying methods. Hot air at $70^{\circ} \mathrm{C}$ consumes lesser drying time and percentage of paddy moisture content is low [23]. Sun drying is performed by two methods such as on mat and on floor. Method of sun drying and moisture content are significantly affects the milling quality of rice and percentage of broken rice [24].

\section{Physical properties of rice kernals}

Paddy husking efficiency mainly depends on paddy varieties, size and shape of rice. The medium rice grain breaks at 
lower moisture content of $10-11 \%$. The lower moisture content of long and short grain has high husking efficiency [25]. The physical properties of rice kernel is shown in the TABLE 1 . The lower moisture content of long and short grain has high husking efficiency [25]. Short grain has higher husking efficiency in rubber roll husker compared to long grain size [13]. Quality of long and short grain rice are depends on degree of milling and energy consumption during processing. High degree of milling improves the head rice yield. Lower degree of milling retains more number of nutrients in grains [26]. Milling quality of the rice is monitored by digital image analysis. Ten verities of rice are subjected to various milling conditions. 3D images are obtained from the result of image analysis (length, perimeter, and projected area). This kind of online monitoring helps to control the conditions of the rice milling operation [27]. Most of the physical properties are varied based upon different cultivators. True density and porosity properties remains constant. Grain length, aspect ratio, porosity plays as a main role to control the degree of milling and loss of selenium. The linear relationship was further observed between degree of milling and loss of selenium [28]. Physical and mechanical properties of grains affects the milling operation. Rough, brown, and milled rice are taken to find the optimum parameters of the milling operation. High friction coefficient values are obtained at wood roller surfaces and lower friction coefficient values are obtained at steel surfaces [29]. Physical properties of the grains plays a main role to design the processing, sorting, sizing, and post harvesting machines used in agriculture field [30]. Degree of milling grains is the main parameter to define the loss of weight percentage of the kernel during milling operation. It also affects the product quality of the rice [31]. Brown rice from the Japonica variety showed the higher intensity in color when compared with the Indica variety. Milling process, on both the varieties tend to grow lighter in color. Higher Degree of Milling (DOM), affects the lightness value and intensity of color on different rice varieties [32]. Degree of Milling influences the overall quality of milled rice kernels. The quality of the rice kernels increases linearly with de-husking process. Whiteness of the milled rice kernels can be measured by using the commercial whiteness meters. These meter measures the kernel whiteness in range from 0-100 and this is generally termed as Whiteness Index. In this index, 0 value corresponds to black surface while 100 represents the whiteness similar to the whiteness of magnesium oxide fumes [33].

TABLE 1

Physical properties of rice kernel

\begin{tabular}{|c|c|c|}
\hline $\begin{array}{c}\text { Grain } \\
\text { length, } \mathrm{l}\end{array}$ & $\begin{array}{c}9.92 \\
(\mathrm{~mm})\end{array}$ \\
\cline { 1 - 2 } $\begin{array}{c}\text { Grain } \\
\text { Width, w }\end{array}$ & $\begin{array}{c}2.47 \\
(\mathrm{~mm})\end{array}$ \\
\cline { 1 - 2 } $\begin{array}{c}\text { Grain } \\
\text { thickness, t }\end{array}$ & $\begin{array}{c}1.95 \\
(\mathrm{~mm})\end{array}$ & \\
\hline
\end{tabular}

\section{Husking characteristics}

The husking of paddy rice has characteristics of husking ratio, husking time and husking index. Photograph of paddy in between rubber rollers before husk removal is shown in the Fig. 2. The paddy dehusking rate increased from $60-90 \%$, as the head brown rice yield (HBY) decrease. The highest HRY are obtained at the dehusking rate of $80 \%$ [34].

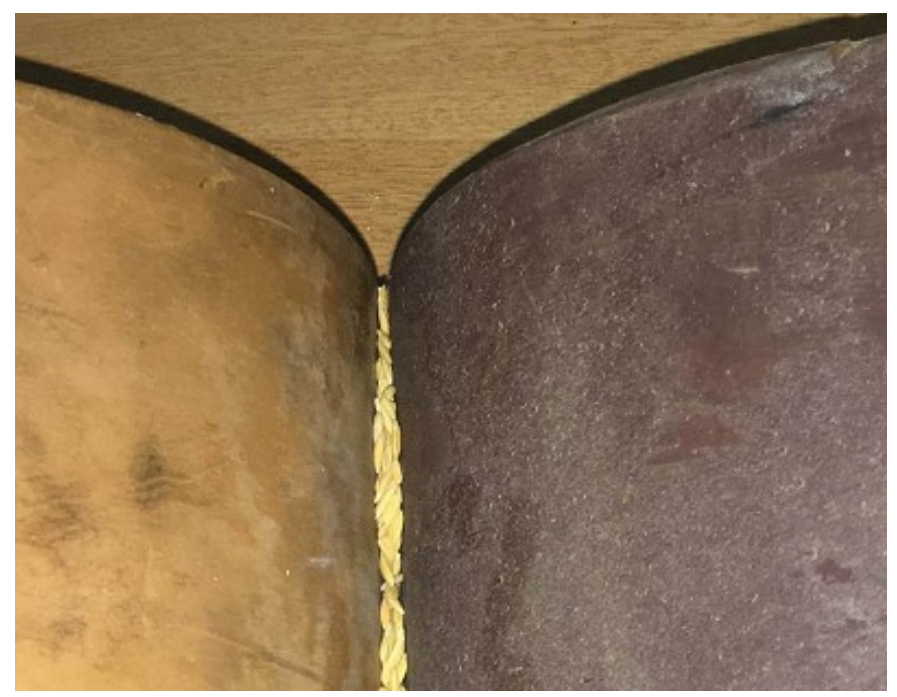

Fig. 2. Photograph of paddy in between rubber rollers before husk removal

\subsection{Husked ratio}

Husked ratio (HR) is defined as ratio of brown rice to input paddy. The four levels of husked ratio (0.6, 0.7, 0.8 and 0.9$)$ on broken brown rice (BBR), broken milled rice (BMR) and rice whiteness (RW) is examined. The BBR increase significantly with increase in HR in the rubber roll husker. The lowest BMR is obtained at the HR of 0.8. The grain brokes at the husking operations in rubber roll husker, at HR of 0.9. The rice whiteness decreased significantly as the HR increased [35]. The husking ratio of grains in a rubber roll husker depends on physical properties of paddy, clearance between rolls and speed difference of the two rolls. The husking ratio of awned and de-awned paddy in Hashemi and binam variety decreased as moisture content increased. The effect of de-awning and moisture content has high significant on husking ratio [36].

\subsection{Husking time}

The analysis of variance shows that paddy variety, deawning and moisture content significantly affected hulling time of the paddy in the rubber roll husker. The husking time of awned and de-awned paddy of Hashemi and Binam varieties increased as moisture content increases. The hulling time of awned paddy is higher than that of de-awned paddy and there is a decreasing trend in husking time with decreasing moisture content [36]. 


\subsection{Husking index}

The husking index of awned and de-awned paddy of Hashemi and Binam varieties decreased as moisture content increased. The higher husking index is observed for de-awned paddy at lower moisture content [36].

\section{Paddy moisture content}

The moisture content has high impact during dehusking [15]. The three level of moisture content (8 to $10 \%, 10$ to $12 \%$ and 12 to 14\%) is considered. The optimum moisture content of paddy rice in milling process is 12 to $14 \%$ w.b [2]. The harvested rough rice has lesser moisture content with higher number of fissured kernals and it is reduced HRY [19]. Three levels of paddy moisture content (8-9, 10-11 and $12-13 \%$ w.b) is conducted in Rice Research Institute of Iran (RRII). The average broken kernel percentage increased and husking index decreased, as the paddy moisture content increases. The head brown rice decreased as the paddy moisture content increased from 8-9\% to $12-13 \%$. The paddy moisture content of $8-9 \%$ is the most appropriate level of paddy husking in rubber roll husker. [1] The breaking force decreased as the moisture content of paddy and brown rice is increased from 6 to $12 \%$ w.b. The maximum and minimum head rice yield (HRY) are obtained at moisture content of 6 and $12 \%$. The moisture content decreased from 12 to $6 \%$ as the breaking force increased [37]. For the three common rice varieties investigated namely Ali Kazemi, Hashemi and Hasani the average hulling waste significantly increased from 14.100 to $20.926 \%$ as the increasing of drying temperature from 33 to $53^{\circ} \mathrm{C}$ at interval of $5^{\circ} \mathrm{C}$. The mean hulling waste significantly decreased from 22.016 to $14.605 \%$ as increasing the moisture content of grain from 8 to $16 \%$ w.b. at interval of $2 \%$ w.b. The hulling waste and whitening waste is higher in Ali Kazemi and Hasani varieties. The minimum hulling waste is obtained in hasani variety at drying temperature of $32^{\circ} \mathrm{C}$ and paddy moisture content of $14 \%$. The maximum whitening waste is obtained in Hasani variety at temperature of $53^{\circ} \mathrm{C}$ and paddy moisture content of $8 \%$ [15]. The two major factors that determine the milling quality of rice are paddy harvest time and its moisture content for milling process. Milled rice breakage and ratio of cracked kernels are also considered to study the effect of these factors. Five harvest times of 24, 27, 30, 33, 36 days after fifty percent flowering and four milling moisture contents of 8-9, 10-11, $12-13$, and $14-15 \%$ dry basis for the research was considered. The final conclusion reveals about the gain of least Milled Rice Breakage and Ratio of Cracked Kernels. The most suitable situations for harvesting and milling were determined as harvesting at 30 days after fifty percent flowering and milling at Paddy moisture content (PMC) of 8-9\% dry basis [21]. Milled rice has the good ability to absorb water at a faster rate than the brown rice. The protective layers of the milled rice are removed in the milling operations. It reveals about the endosperm portion of the milled rice is easy to absorb the moisture content [40].Brown rice having the layers such as surface lipids and wax content. These layers are not allow the water into the kernel [41]. Grains having different moisture content are milled at various levels of milling. The results are evaluated but not found in satisfied level [42]. Bran removal from the kernels of brown rice with moisture content is high and also directly proportional to the high degree of milling. This results in removal of bran from the brown rice is high when compared it with the milled rice at high degree of milling [43].

\section{Rollers speed}

The six levels of rollers differential speed (1.5, 2.2, 2.9, 3.6, 4.3 and $5 \mathrm{~m} / \mathrm{s}$ ) is conducted in RRII. The amount of broken rice decreased when the roller differential speed is gradually increased from 1.5 to $5 \mathrm{~m} / \mathrm{s}$. The maximum husking index was recorded at rollers speeds of $2.9 \mathrm{~m} / \mathrm{s}$ [44]. The process parameter (husked rice ratio, percentage of raw broken, output, rubber consumption) of rubber roll husker with different linear speed is calculated. The linear speed varies from 12.5 to $20 \mathrm{~m} / \mathrm{s}$ at interval of $1 \mathrm{~m} / \mathrm{s}$. The fast linear speed contained high husked ratio, percentage of raw broken and output and also less rubber consumption. The low linear speed showed higher rubber consumption [45]. The broken and cracked grains increased significantly with increase of rotational speed [46]. Rubber roll clearance is varied from 0.4 to $2.4 \mathrm{~mm}$. The optimal rubber roll clearance for husking is $1.8 \mathrm{~mm}, 1.5 \mathrm{~mm}$, and $1.3 \mathrm{~mm}$ [13].

\section{Roller pressure}

The process parameter (husked rice ratio, percentage of raw broken, output, rubber consumption) of rubber roll husker with different roll pressure is calculated. The roller pressure is varied from 4 to $7 \mathrm{~kg} / \mathrm{cm}$ at interval of $0.5 \mathrm{~kg} / \mathrm{cm}$. The roll pressure $7 \mathrm{~kg} / \mathrm{cm}$ had higher husked rice ratio, output, and percentage of raw broken and rubber consumption [45]. The roll-roll pressure is propositional to system load and motor power. Equivalent coefficient of friction of fast and slow rolls decreases with the increase of roll-roll axial pressure [47].

\section{Feed rate}

The single grain feed has better husking performance compared to random grain feed. Husking ratio for horizontal grain feed is higher than that of vertical grain feed [13]. The process parameter (husked rice ratio, percentage of raw broken, output, rubber consumption) of rubber roll husker with different feeding is calculated. The feeding is varied from 135 to $185 \mathrm{~kg} / \mathrm{cmh}$ at interval of $10 \mathrm{~kg} / \mathrm{cmh}$. The higher feeding rate showed higher percentage of raw broken and output but lesser husked rice ratio and rubber consumption [45]. Feed rate produces a small impact on equivalent coefficient of friction on fast and slow rolls [48]. 
Three level of feed $(0.014,0.033$ and $0.088 \mathrm{~kg} / \mathrm{s})$ is performed to determine the husking efficiency of rubber roll husker. The higher and lower feed rate shows the lesser husking efficiency. Feed rate of $0.033 \mathrm{~kg} / \mathrm{s}$ is the optimum for husking [34].

\section{Fissures}

Rice kernel fissuring is the major problem in rice milling industry. It reduces the Head rice yield [3]. Paddy rice have fissure before drying because fissure occur during harvesting and storage [49]. Rice kernels break during dehulling and milling because of the propagated fissure kernels. Fissure is the line of crack produced in rice kernels. The fissuring percentage is high at drying temperature of $80^{\circ} \mathrm{C}$. Low drying temperature defines the low fissuring percentage [50]. Fissure of the kernels are created or propagated during drying process and fissure are developed in hulling operation. The bending strength and fracture energy of the fissured rice kernels is lower than that of sound rice kernels [18].

\section{Rubber roll wear}

Rubber roll wear is based on the roller pressure, feed rate, linear speed and roller differential linear speed. The roller pressure varies from 4 to $7 \mathrm{~kg} / \mathrm{cm}$ at interval of $0.5 \mathrm{~kg} / \mathrm{cm}$. The high roller pressure consumes high rubber content. The fast linear speed varies from 12.5 to $20 \mathrm{~m} / \mathrm{s}$ at interval of $1.5 \mathrm{~m} / \mathrm{s}$. Low fast linear consumes high rubber roll material. Feeding is varied from 135 to $182 \mathrm{~kg} / \mathrm{cmh}$ at interval of $10 \mathrm{~kg} / \mathrm{cmh}$. The high feed rate consumes less rubber material and low feed rate consumes high rubber material. The differential linear speed varies from 2.3 to $3.3 \mathrm{~m} / \mathrm{s}$ at interval of $0.2 \mathrm{~m} / \mathrm{s}$. the high differential linear speed consumes high rubber material and low differential linear speed consumes less rubber material [45]. The harder rubber require a low normal force to achieve given husked ratio. The constant shear stress is likely reduce the wear on rubber roll surface [50]. Wear index indicates the polishing behavior and degree of milling these are the two parameters are mainly considered for wear resistance evaluation during milling operation [11]. Carbon nano fibers, carbon nanotubes are more efficient than organo clays used as a nano modifier in the rubber compound these two constituents improves the wear resistance and mechanical properties of the rubber roller instead of using PEEK (Poly Ether Ether Ketone), PTFE (Poly Tetra Fluro Ethylene). Tribological effects of nano reinforcement strongly depends upon the various testing parameters of the tribosets [51].

\section{Conclusion}

The parameters that affect the rice breakage and rubber roll wear depends on the type of harvesting, drying temperature, drying methods, physical characteristics of paddy, husking characteristics, paddy moisture content, rubber roller speed, rubber roll pressure, paddy feed rate, fissures and rubber roll wear. so for polyurethane and food Quality Nitrile rubber compound has been developed to test the shelling efficiency and rice breakage. Fresh paddy contains $28 \%$ of moisture content and this leads to increase in rice breakage during rice milling. Temperature adopted for drying should be altered based on the level of moisture content. Each paddy has different kernel dimension and it leads to rice breakage during the husking operations. Rice breakage depends on husking ratio, husking time and husking index. The optimum moisture content in rice milling is $12-14 \%$ w.b, rice breakage is low at this moisture content. Higher roller speed leads to increase in rice breakage and in turn roller operated at lower speed leads to unhusked rice. So the optimum roller speed for husking operation in rice milling is $2.9 \mathrm{~m} / \mathrm{s}$. Rice breakage is also based on the feed rate in the rubber roll huller. In friction process, crack is developed in the rice kernel and it leads to rice breakage. Rubber roll material wears due to the friction process of paddy de-husking. Rice breakage is also varied based on rubber roll hardness.

\section{REFERENCES}

[1] M.R. Alizadeh, I. Bagheri, Int. J. Nat. Eng. Sci. 3(3), 139-143(2009).

[2] S. Afzalinia, M. Shaker, E. Zare, Can. Biosyst. Eng. 46 (3), 63-66 (2004).

[3] J. Buggenhout, K. Brijs, I. Celus, J. Delcour, Food Eng. 117 (3), 304-331 (2013).

[4] E. Rodante Tabiena, S. Omar, P.B. Samontea, E.R. Tiongcob, J. Cereal Sci. 49, 122-127 (2008).

[5] H. Takai, I.R. Barredo, J. Agric. Res. 26, 441-448 (2003).

[6] D. Mohapatra, S. Bal, Biosyst. Eng. 88 (3), 337-342 (2004).

[7] B.K. Yadav, V.K. Jindal, J. Food Eng. 86, 113-121 (2007).

[8] T.Y. Yan1, J.H. Hong, J.H. Chung, Biosyst. Eng. 92 (3), 317-323 (2005).

[9] P. Kumar Satya, Ch. Someswararao, S.K. Das, Innov. Food Sci. Emerg. 22, 175-179 (2013).

[10] Dauda, Solomon Musa1, Adeoye, Peter Aderemi1, Bello, Kehinde, Agboola, Int. J. Agron. Agric. Res. 2 (1), 15-21 (2012).

[11] D. Mohapatra, S. Bal, Food Bioprocess. Tech. 5, 2111-2119 (2012).

[12] S. Puri, B. Dhillon, N. Singh Sodhi, Int. J. Adv. Biotechnol. Res. 5, 474-489 (2014).

[13] D. Shitanda, Y. Nishiyama, S. Koide, J. Sci. Res. Develop. 3 (9), 01001 (2001).

[14] M.-Ch. Li, Y. Zhang, U.R. Cho, Mater. Design 63, 565-574 (2014).

[15] Babamiri, N. Salehi, E. Askari Asli-Ardeh, Int. J. Agric. Crop. Sci. 6 (9), 529 (2013).

[16] M.A. Wirakartakusumah, D. Lund, J. Food Sci. 43 (2), 394-396 (1978).

[17] Yang, W. Jia, C.C, Siebenmorgen, T.J, Pan, Z. Cnossen, A.G. Biosyst. Eng. 85 (4), 467-476 (2003).

[18] H. Chen, T. Siebenmorgen, B. Marks, T. Asae, 40 (4), 1133-1139 (1997).

[19] A. Iguaz, M. Rodriguez, P. Virseda, J. Food Eng. 77 (4), 803-809 (2006). 
1880

[20] B. Toshizo, Jarq-Jpn. Agr. Res. Q. 6 (2), 113-116 (1971).

[21] J. Aquerreta, A. Iguaz, C. Arroqui, P. Vírseda, J. Food Eng. 80.2, 611-618 (2007)

[22] A.G. Cnossen, M.J. Jimenez, T.J. Siebenmorgen, J. Food Eng. 59.1, 61-69 (2003).

[23] S. Wongpornchai, K. Dumri, S. Jongkaewwattana, B. Siri, Food Chem. 87(3), 407-414 (2004).

[24] P.B. Imoudu, A.A. Olufayo, Bioresource Technol. 74.3, 267-269 (2000).

[25] S.M.A. Razavi, R. Farahmandfar, Int. Agrophys. 22 (4), 353-359 (2008).

[26] R. Poritosh, T. Ijiri, H. Okadome, D. Nei, T. Orikasa, N. Nakamura, T. Shiina, Journal Of Food Eng. 89.3, 343-348 (2008).

[27] B.K. Yadav, V.K. Jindal, Comput. Electron. Agr. 33.1, 19-33 (2001).

[28] K. Liu, K. Liu, X. Cao, Q. Bai, H. Wen, Z. Gu, J. Food Eng. 94.1, 69-74 (2009).

[29] P.C. Corrêa, P.C. Corrêa, F. Schwanz da Silva, C. Jaren, P.C. Afonso, I. Arana, J. Food Eng. 79.1, 137-142 (2007).

[30] M.G. Varnamkhasti, H. Mobli, A. Jafari, A.R. Keyhani, M.H. Soltanabadi, S. Rafiee, K. Kheiralipour, J. Cereal Sc. 47.3, 496-501 (2008).

[31] M.D. Shams-Ud-Din, K.R. Bhattacharya, J. Food Sci. Tech. 13.2, 99-105 (1978).

[32] Bk Yadav, Vk Jindal, J. Food Eng. 86, 113-121 (2008).

[33] L. Lamberts, L. Bie, G. Vandeputte, W. Veraverbeke, V. Derycke, Man Wd, Delcour, J. Food Chem. 100, 1496-1503 (2007).

[34] M.R. Alizadeh, M.H. Rahmati, Res. J. of Biol. Sci. 6(4), 153-157 (2011).

[35] M.R. Alizadeh, R. Mohammad, Aus. J. Crop. Sci. 5.5, 562 (2011).
[36] S. Minaei, M.R. Alizadeh, M.H. Khoshtaghaza, T. Tavakoli, Am-Eurasian J. Agric. \& Environ. Sci. 2(1), 01-05 (2007).

[37] M. Alizadeh, A. Dabbaghi, F. Rahimi-Ajdadi, Dept. Agric. 36, 3186-3189 (2011).

[38] S. Firouzi, M.R. Alizadeh, Int. J. Biosciences. 3.10, 133-138 (2013).

[39] O. Kunze, M. Choudhury, Cereal Chem. 49, 684-697 (1972).

[40] T. Siebenmorgen, J. Meullenet, Ame.r Assoc. of Cereal Chem., 301-328 (2004).

[41] D.B. Bechtel, P.Y Bechtel, B. Donald, Y. Pomeranz, Am. J. Bot. 64, 966-973 (1978).

[42] P. Roy, I. Tsutomu, H. Okadome, N. Daisuke, T. Orikasa, N. Nakamura, T. Shiina, Jk Food Eng. 89, 343-348 (2008).

[43] H. Desikachar, R. Rsn, J. Food Sci. Tech. 2, 110-112 (1965).

[44] S. Firouzi, M. Alizadeh, S. Minaei, Int. J. Agric. Biologic. Sci. 1(1), 1-4 (2010).

[45] J. Ruan, X. Liu, G. Xiang, Cons. Electron. Commun. Net., 337-340 (2011)

[46] A.M. Reza, S. Minaei, F. Rahimi-Ajdadi, M. Hadi, Int. J. Agric. Crop. Sci. 5.3, 298 (2013).

[47] Jing-Lan, R.C. Xiang-Fa, Ieee Icae. 139-143 (2011).

[48] C. Nguyen, O. Kunze, Pap-Amer. Soc. Agric. Eng. 61, 63-68 (1981)

[49] Y. Lan, Q. Fang, M.F. Kocher, M.A Hanna, Int. J. Food Prop. 5 (1), 205-215 (2002).

[50] A. Baker, R.S. Dwyer-Joyce, C. Briggs, A. Brockfeld, J. Eng. Tribol. 226 (6), 516-528 (2012).

[51] J. Karger-Kocsis, D. Felhös, Tribol. Int. Eng. Ser. 55, 304-324 (2008). 